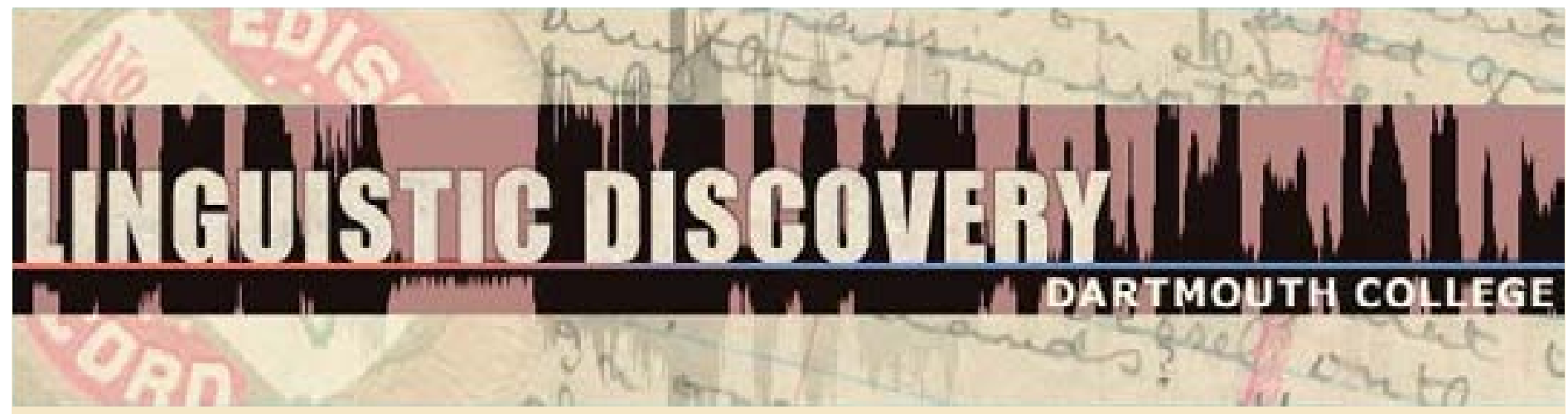

\begin{tabular}{|l|}
\hline Volume 9 \\
Issue 1 \\
2011 \\
\hline
\end{tabular}

\title{
Coordination in Pribilof Islands Unangam Tunuu
}

Anna Berge

University of Alaska Fairbanks

doi: 10.1349/PS1.1537-0852.A.386

url: http://journals.dartmouth.edu/cgi-bin/WebObjects/ Journals.woa/1/xmlpage/1/article/386 


\section{Coordination in Pribilof Islands Unangam Tunuu Anna Berge}

This paper provides a detailed analysis of conjunctive, disjunctive, and adversative coordination in the Pribilof Islands variety of Unangam Tunuu (Aleut). Although Unangam Tunuu prefers clause-chaining to coordinate structures, it nevertheless makes frequent use of coordination; and while Unangâx coordination is not typologically unusual, there are many subtleties in the use and distribution of particular coordinating particles. In this paper, I compare clause-chaining and coordination as strategies for expressing coordination in Unangam Tunuu; I examine the varieties of Unangâx coordinating particles, their sources and functions, their uses in different types of coordinating structures, and the effects of coordination on syntax.; and I show some ways in which syntactic, semantic, pragmatic and idiolectal factors affect the use of coordination or of a particular coordinating strategy.

\section{Introduction}

In this paper, I will look at some general features of coordination in Unangam Tunuu (Aleut), and specifically, the variety spoken on the Pribilof Islands off the coast of Alaska and north of the Aleutian Chain. Existing descriptions of coordination in Unangam Tunuu are sparse in the details, in part because Unangam Tunuu is a clause-chaining language with a preference for combining clauses via subordinate rather than coordinate structures. Furthermore, coordination in Unangam Tunuu is typologically not unusual, and although there are a large number of coordinating particles with overlapping but non-identical meanings, this is because of the morphosyntactic possibilites of the verbs they derive from. However, there are many subtle and interesting differences in their uses, and these need a more complete description to more fully understand how coordination works in Unangam Tunuu. In this paper, after a brief introduction to the more common issues which arise in studies of coordination (section 2), I will look at Unangax coordination strategies (section 3), the varieties of coordinating particles and their sources and functions (section 4), usages of coordinators in different types of coordinate structures (section 5), and effects of coordination on syntax in general (section 6).

\section{Overview of Coordination}

Coordination has broadly been defined as a means of linking like structures at the same hierarchical level, cf. Dik (1968:[25]): “A coordination is a construction consisting of two or more members which are equivalent as to grammatical function, and bound together at the same level of structural hierarchy by means of a linking device." Dik's definition still captures today the essential characteristics of what is generally understood as coordination, although the meaning of 'equivalent,' 'grammatical function,' 'structural hierarchy,' and 'linking device,' are all debated at length in the literature. For example, it has long been recognized that two elements are not judged to be equivalent solely on the basis of syntactic structures, as the following example with different verb moods illustrates: 


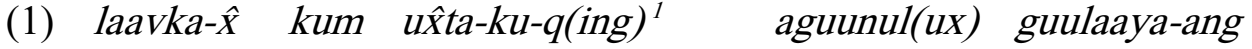 \\ store-ABS DUB go.to/reach-IND-1SG or take.a.walk-INTEN.1SG \\ 'I might go to the store or I will take a walk' $(\mathrm{K})^{2}$}

One reason for the emphasis on equivalent, symmetric, or similar items is to distinguish coordination from the more general concept of clause linkage, which includes subordination, coordination, and discourse continuity. The boundary between coordination, in which the coordinated elements are symmetrical, and subordination, in which one element is dependent on the other, is itself vague. Dependence is a matter of degree, and in connected discourse everything is dependent to some degree on its context (Givón 2001:327). It is, for example, possible to link clauses which are syntactically dependent but semantically independent, and vice versa. The difficulty in defining the boundaries of dependence is also reflected in the linking strategy; for example, numerous tests are proposed to distinguish coordinating from subordinating particles (cf. Dik 1968:34ff), but they are not universally valid (Haspelmath 2007:46-47), and the same particles can be used for different functions (e.g. both coordinate and subordinate functions, Haspelmath 2007:48, quoting from Culicover and Jackendoff 1997, or different coordinate functions, cf. Payne 1985:7ff).

Whatever one's precise definition, the key components of definitions of coordination contain the functional equivalence of two or more elements and the strategy used to coordinate these. Functional equivalence can refer to syntactic, semantic, pragmatic, or cognitive equivalence (and both Mauri 2008 and Blühdorn 2008 distinguish the different levels of equivalence by using separate terminologies); and a coordinating strategy can consist of a coordinating particle or it can simply involve a strategy such as juxtaposition, clause-chaining (Givón 2001:348), the use of intonation (Mithun 1988), and so forth. For the most part, however, studies of coordination have given more weight to descriptions of syndetic coordination, or coordination with a particle, unless a language makes little use of particles for this purpose.

If coordination is a definable means of combining equivalent structures, this equivalency should be manifest in some way when comparing clause-combining strategies in different languages. This may be what Haspelmath has in mind when he suggests that a construction may be coordinate if it is systematically used to translate an English coordinate construction (Haspelmath 2004:3). However, the variations in the types of equivalence and strategies for indicating equivalence make crosslinguistic comparison less obvious (and cf. Fabricius-Hansen, et. al. 2005 for a discussion of problems in translating coordinators between related languages as a result of different domains of use). Further, the study of the typology of coordination is relatively recent, and there are still large gaps in the description of coordinate structures in most

\footnotetext{
${ }^{1}$ Parentheses in the Aleut examples indicate part of a word which is ellided or unexpressed by the speaker during elicitation of the examples. Some of these are motivated by syncopation rules, as in $i \hat{x} a m(a)$ nakuर, pronounced $i \hat{x} a m$ 'naku $\hat{x}$ 'he, she, it is good, fine,' while others are a reflection of frequent apocope of final syllables, as in $\operatorname{amay}(u x)$, pronounced amay 'and, and also.'

${ }^{2}$ Expressions were generally elicited of multiple speakers originating from both St. George and St. Paul in the Pribilofs. Many examples of more complex sentences are unique to a speaker, in the sense that different speakers chose to express the same thing slightly differently; in these cases, the speaker is identified in parentheses following the English gloss. With many simpler sentences, most if not all speakers provided the same Unangax form, in which case no single speaker is identified. In a few cases, a dialect other than Pribilovian is represented, and this is also noted after the English gloss.
} 
of the less-well described languages. To this end, recent studies often focus on the systematic mapping of syntactic and semantic features of coordinated structures in different languages.

Common investigative questions of coordination include (1) whether or not a language uses coordinating particles, and if so, (2) the pattern of particle use it exhibits (e.g. a particle for each coordinand or only one, pre- or postposed to the coordinand, etc.), (3) the types of constructions which can be coordinated (with a coordinating particle, as opposed to subordinated or juxtaposed) and the structural levels which are coordinated (NPs, VPs, clauses, etc.), (4) the syntactic and/or semantic sources of the coordinating particle or structure, and (5) the effect of coordination on syntax. Mauri (2008), Haspelmath (2004, 2007), and in a somewhat different vein Rousseau (2007) also discuss a number of semantic concepts which have an effect on or which motivate the use of coordinate structures. For example, traditionally, three types of coordination are proposed: conjunctive (and), disjunctive (or), adversative (or); rarely, other more restricted types are also proposed, such as causative (for). However, each type has common semantic subtypes which may or may not be reflected morphosyntactically. ${ }^{3}$ Thus, conjunction often expresses the simultaneous, sequential, or atemporal nature of the relationship between two clauses, or it may express a natural pair (as in mother and father), a natural progression, etc. Disjunction permits the expression of a choice between two or more members of a set of possibilities (as in do you want the fish or the meat dinner?) or the expression of a set of options (as in I usually have coffee or tea in the mornings); there are some more specific distinctions which might be made, as in exclusive disjunction (one disjunct or the other, but not both) and inclusive disjunction (one or both disjuncts), etc. Adversative coordination allows the expression of some kind of contrast, whether it is the denial of an expectation, the correction of an error, or an antonymic or oppositional relationship. Rousseau (2007:32ff) is more inclusive of the more rarely used particles and groups the coordinators into 4 categories based on the relations they impose: those which express junction (conjunction or disjunction), antecedence and consequence (e.g. causative), adversative relations, and concession (e.g. French pourtant). Rousseau (2007) and Mauri (2008) further see the expression of realis and irrealis as an important factor in the difference between conjunctive and disjunctive coordination, although how this is reflected morphosyntactically is unclear.

Regardless of the groups identified, typologically, the most general type of coordination and the one with the broadest range of application is conjunctive coordination. For example, a description of conjunction often seems to satisfy descriptions of the other types of coordination; conjunctive structures can be used to express disjunction or adversity; conjunction can often be found at all syntactic levels, whereas other types may be more restrictive (thus, adversative and concessive coordination are often found at clause-level only, Rousseau 2007:38); and so forth. This has sometimes led to descriptions of coordination which focus heavily on conjunction alone. Nevertheless, there are often some aspects of non-conjunctive coordination which are not equivalent to conjunction, and a description of coordination in a language will therefore have to include all identified forms of coordination.

In the following investigation of coordination in Unangam Tunuu, I will assume a moderately traditional definition of coordination as the linking of two or more similar or equivalent items, with similarity being syntactic, semantic, or pragmatic in nature. Items can be linked via clause chaining, juxtaposition, and the use of a coordinating particle. Clause chaining is more widely used for subordination, and subordination is preferred to coordination in general,

\footnotetext{
${ }^{3}$ Payne (1985) distinguishes five types of coordination, however they involve variations or combinations of the three logical operators and, or, and not.
} 
as we will see; and while juxtaposition is a possible strategy for all types of coordination in Unangam Tunuu, it is invariant in its form, and it is also not the primary method of indicating coordination. Therefore, although I will discuss all three below (section 3), I will primarily focus on coordination with a particle. I will limit the investigation of coordination to the three most commonly identified types, conjunctive, disjunctive, and adversative coordination, although there is a causative structure which may be arguably considered coordinative (section 4.5). Finally, I will largely confine myself to coordination in the speech of the Pribilof Islanders. While I do not expect significant structural differences in coordination between the Unanga $\hat{x}$ dialects, however, there are differences both in the coordinating particle used and in the usage of the particles. For example, all dialects have multiple forms of the coordinating particles as a result of their relatively transparent morphological derivation (e.g. the verb $a$ - 'to be' and common derivational and inflectional morphology); however, the different dialects may prefer different derivational forms. Thus, the Western dialect, Atkan, typically uses a disjunctive coordinator morphologically formed from a passive construction, whereas the same coordinator in Eastern and Pribilovian is based on an active construction. Further, all possible forms of a coordinator are not necessarily used within a given dialect. Some dialect differences are noted in the footnotes and come especially from the works of Bergsland (1994, 1997), Berge and Dirks (2009), and my fieldnotes; however, dialectal differences will require further study.

\section{Strategies for Expressing Coordination in Unangam Tunuu}

In Unangam Tunuu, coordination is effected via clause chaining, the use of coordinating particles, and juxtaposition. In a clause chain, sentences are constructed by linking a series of dependent (or subordinate) clauses and an independent clause. In this case, one does not typically speak of clause coordination, but rather of clause combining (which is actually neutral with respect to the hierarchical relationship of the clauses). Clause chaining results in structural subordination, but it does not necessarily result in semantic subordination. If a clause is semantically subordinate, it is often less foregrounded than the superordinate clause, as in example (2) (see also example (8)):

\section{(2) ungachi-lix txin anĝisi-da \\ sit-CONJ self enjoy-IMP \\ 'sitting, enjoy yourself' = 'sit and enjoy yourself'}

Subordination is generally preferred to coordination as a clause-linking strategy. In texts from older sources (cf. Bergsland and Dirks 1990), and certainly in narrative language, both phrase and clause coordination are relatively infrequent, particularly for conjunctive and disjunctive functions; instead, individual elements of otherwise complex phrases or clauses are expressed as separate clauses. Example (3) illustrates this preference for chaining with the conjunctive verb mood (not to be confused with conjunctive coordination), one of the most common subordinate moods in chains, and a common strategy to express what might otherwise be conjoined. The conjunctive mood is inflectionally defective in that it generally does not indicate person or number (although these can be indicated with non $-3^{\text {rd }}$ person enclitic pronouns or with anaphoric inflection) and many conjunctive clauses do not repeat the tense/aspect information found on the main verb. The third clause in the chain is comitative, here signaled by agiita- 'be.together.with' 
in the conjunctive mood; comitative constructions are a common alternative to conjunctive constructions and are also a common source of coordination cross-linguistically:

$\begin{array}{lll}\text { (3) saaqudgi-m ilan braata-ning } & \text { awa-lix } \\ \text { summer-REL in brothers-1SG.POS/PL.POSM } & \text { work-CONJ } \\ \text { 'in the summer when my brothers, working,' } & \end{array}$

ulagi-lakan a-gu-ng(in)

be.at.home-NEG.CONJ AUX-COND-3PL

'were not at home'

braata-ng kinguughi-i amayux

brother-1SG.POS/SG.POSM young-3SG.POS/SG.POSM.ABS and

maama-ng agachiida-a agiita-lix

mother-1SG.POS/SG.POSM alone-3SG.POS/SG.POSM.ABS be.together.with-CONJ

'together with just my younger brother and my mother,'

ulagi-lix a-gu-ung
be.at.home-CONJ AUX-COND-1SG
'I was at home' (OM-Eastern dialect)

In chained structures involving subordination of one or more clauses, disjunction can be expressed by attaching the enclitic negative -ulux to a verb in the conditional mood in the first clause, creating a structure meaning 'if not X, Y,' as illustrated in example (4); this structure is the source of disjunctive markers in Unangam Tunuu:

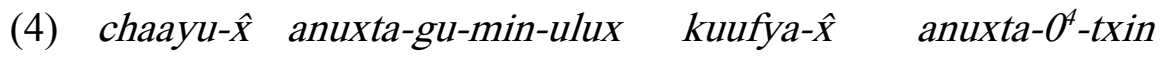 tea-ABS want-COND-2SG-NEG coffee-ABS want-ZERO-2SG 'if you don't want tea, do you want coffee?' = 'do you want tea or coffee?' (S)}

The equivalent of adversative coordination can be expressed in Eastern Unangam Tunuu in chained subordinate structures with one of several postbases, as in -Vgali- 'in vain, to [verb] but, although [verb]' (from - V ga - 'to [verb] in vain,' possibly related to the optative mood marker, cf. Fortescue, et.al. 1994:434; the symbol $-V$ - indicates a vowel), illustrated in example (5); however I have not found examples of this in my Pribilovian texts. This postbase is similar to the adversative particle taga $\hat{x}$ (although a historical connection has not been shown):

\footnotetext{
${ }^{4}$ The zero participial mood, called the general participial by Bergsland (1997), is recognized by the absense of a mood marker; in this paper it is indicated with the symbol ' 0 ,' although in standard orthography, this symbol is not used (the word in this example would be written anuxtatxin).
} 
(5)

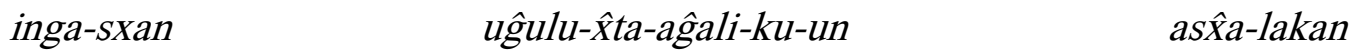

throw.with.spear-CONJ.AN hit.with.spear-PERF-do.in.vain-IND-4SG kill-NEG.CONJ

'he threw and hit him but did not kill him.' (Bergsland 1994:476, Eastern dialect)

Not all clause chains are necessarily to be understood as the linking of subordinate and superordinate clauses, however. Many chained, nonparallel structures are in fact coordinated. In example (6), the first clause is headed by a verb in the conjunctive mood and the second by a verb in a superordinate mood. ${ }^{5}$ Though the clauses are not syntactically parallel as a result of the different verb moods, they are semantically parallel and arguably hierarchically parallel, and they are explicitly coordinated in this case with the use of the conjunctive particle amayux 'and, and also':
ilaasa-ning
guusti-lix
$\operatorname{amay}(u x)$
taya-ang(an)
$a \hat{g}(i)-k u-q i n g$
friend-1SG.POS/PL.POSM visit-CONJ and
shop-INTEN.1SG
AUX-IND-1SG
'(I'm going to) visit my friends and I'm going to go shopping' (M)

Despite a preference for subordinate structures and clause chaining, coordination by means of a coordinating particle is an available strategy for clause combination in Unangam Tunuu, and has been for some time. Unangam Tunuu has a robust set of conjunctive, disjunctive, and adversative (and possibly causal) coordinating particles (Bergsland 1997:104) which have been attested in some of the earliest collected texts, as evidenced by Bergsland's (1994) references in his dictionary entries. Both coordinated and subordinated structures may be available strategies, although subordination is often the more stylistically preferred, as in examples (7) and (8):

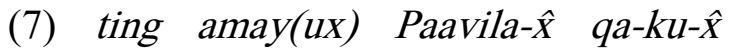 \\ $1 \mathrm{SG}$ and Paul-ABS eat-IND-3SG \\ 'Paul and I are eating'}
(8)
Paavilâx agiita-lix
qa-ku-qing
Paul
be.together.with-CONJ
eat-IND-1SG
'I am eating together with Paul' = 'Paul and I are eating'

The conjunction of $1^{\text {st }}$ person and another person in example (7) differs from both the preferred Eskimo construction (Inuttut Puulilu nirivuguk 'and Paul we two are eating'), which might have been expected given the family relationship between Unangam Tunuu and the Eskimo languages, and the Russian model (мы с павлом едим 'we with Paul are eating'), which one might have expected because of the long-lasting and important influence of Russian on Unangam Tunuu. While there may be some influence from English (or Russian) on the expression of possession today (e.g. ting braata-ng '1SG brother-1SG.POS/SG.POSM' = 'my brother'), the Unangax coordinated structure in this example differs from analogous English structures both in

\footnotetext{
${ }^{5}$ The predicate of the superordinate clause is a periphrastic construction involving a main verb in the intentional and an auxiliary in the indicative; but rules governing inflection and control in periphrastic constructions need further exploration.
} 
word order of the conjuncts and in concord with the verb. Coordinated structures of this type are attested in the $19^{\text {th }}$ century (cf. examples from Bergsland 1997:196) and are probably native constructions, even if stylistically dispreferred.

It should here be noted that in addition to a preference for subordinate clauses, there is also a preference for subordination within phrases when the coordinated items are semantically unequal in some way, rather than coordination, as in example (9); a coordinated structure such as xliiba $\hat{x}$ $\operatorname{amay}(u x)$ maasla $\hat{x}$ 'bread and butter' is regarded as unnatural in this context:
xliiba-m maasla-gi $i-i$
qa-ku-qing
bread-REL butter-have.TRANS-3SG.POS/SG.POSM.ABS eat-IND-1SG
'I'm eating bread provided with butter/buttered bread' (= 'I'm eating bread and butter')

In recent elicitations, coordinate structures are more common than formerly in narratives, and they are common in some stock phrases, elicited sentences, and conversations. In the Pribilof Islands, for example, the dual anakix 'parents' used in the Atkan and Eastern dialects of Unangam Tunuu is unknown, and the coordinate structure anaada $\hat{x}$ amay(ux) adaada $\hat{x}$ 'mother and father' is used instead (an example of Haspelmath's 'natural coordination'). It is possible that conversational style may generate and support more coordinate structures than narrative style, although coordinate structures tend to be rare in oral language (Mithun 1988:339). Unfortunately, documentation of conversational style in Unangam Tunuu is too recent to do more than speculate about the usage of coordination. In contemporary Pribilof Islands Unangam Tunuu, coordination is by far more common than subordination for expressing adversative relations:

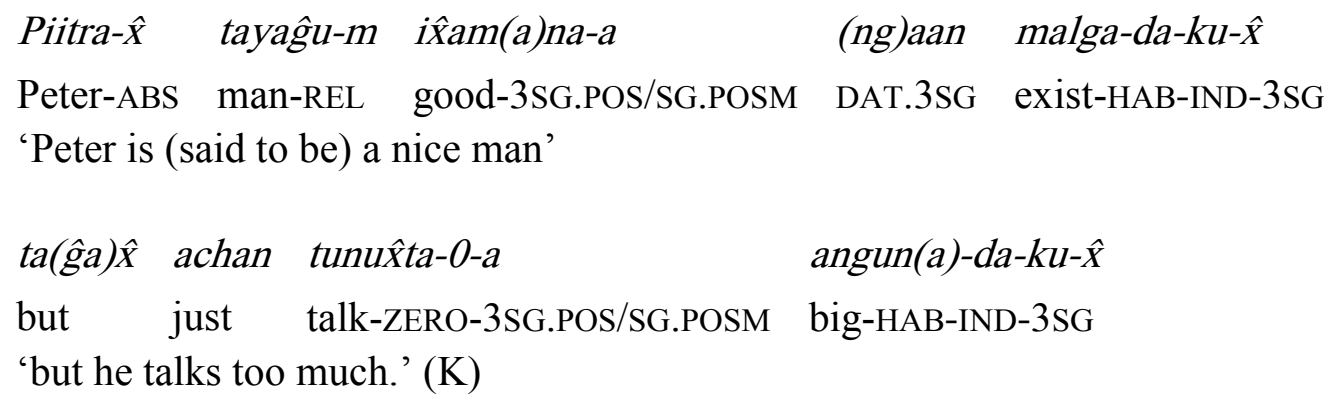

Finally, juxtaposition, or the coordination of (usually no more than two) structurally equivalent clauses without a coordinating particle, is possible for all types of coordinative constructions in Unangam Tunuu and is frequently heard in conversation. Intonation generally plays an important role in distinguishing the nature of the juxtaposition (cf. Mithun 1988:332). In example (11), the speaker has misheard, not heard, or forgotten the answer; the disjoined elements are each said with rising intonation, indicating that each element is questioned, but there is no pause between them, indicating that they form a unit:
wan tugida- $\hat{x} \quad$ qan(an) ista-amin aqa-li-0-txin
this month-ABS when say-INTEN.2SG go-again-ZERO-2SG
'where did you say you were going this month,' 


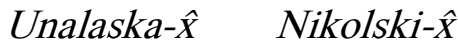 \\ Unalaska-ABS Nikolski-ABS \\ 'Unalaska or Nikolski?' (F)
}

\title{
4. The Unangax̂ Coordinators and Their Sources and Functions
}

All coordinators in Unangam Tunuu come from other sources and have other primary functions. The noun phrase coordinators come from a distal demonstrative, from an adverbial meaning 'also,' or from an original clausal construction, such as comitative or conditional construction, and clausal coordinators have developed from discourse adverbials and the need to express a temporal relationship between clauses, as in 'first...then...' (this supports Mithun 1988:346ff).

\subsection{The particle ama}

The particle ama is a discourse connective ('and then, so') with possible roots as a demonstrative; it is in fact indistinguishable from the distal demonstrative ama 'that one, invisible.' It is also frequently used as an emphatic particle; in these cases it tends to be postposed to the word or clause being emphasized. It is the most common conjunctive coordinator, and probably has a long history as such, judging from comparative evidence: many Eskimo languages have a cognate form amma with the same function (Fortescue, et. al. 1994:24). It is used by all speakers and it can be used as a conjunction in binary constructions (e.g. X ama Y), lists (e.g. X, Y, ama Z), titles, at all structural levels, and with conjunctive mood clause chaining.

The discourse connector and conjunctive coordinator ama also combines with other words which can be used as coordinators. Syntactically, coordinators are not expected to appear in combination, nor as second elements in a combination (Dik, 1968:34). In Unangax̂ combinations with $a m a$, the second elements of these combinations are all transparently from subordinating verbs or adverbs, despite functioning as coordinators on their own. Combinations are often morphologically fused but their derivation is fully transparent to speakers, and there is therefore an option of using a combination of separate lexical items, as in ama kayux 'and also,' or a fused form, as in amayux (ama+kayux 'and+also'). In the former, the second element retains its adverbial character, whereas the fused form functions as a single connecting or coordinating particle. Fused forms involving ama include amaya (from $a m a+y a$ 'and + anaphoric deictic'), amayux (from ama+kayux 'and also'), and amasix (from ama+asix 'and with'). The form most commonly used among speakers from the Pribilofs is amayux, but all other forms are attested as well. Example (12) illustrates the derived form amayux as a discourse connector, and example (13) illustrates its use as a conjunctive coordinator: ${ }^{6}$
$\begin{array}{llll}\text { kum } & \text { txin } & \text { agiita-1(a)ka-txin } & \text { eh } \\ \text { DUB } & \text { 2SG } & \text { together.with-NEG.IND-2SG } & \text { INTER }\end{array}$
'maybe I could come with you?'

\footnotetext{
${ }^{6}$ The identification as amayux or amaya of a coordinator pronounced amay in normal speech was made as a result of repetition using deliberate speech.
} 


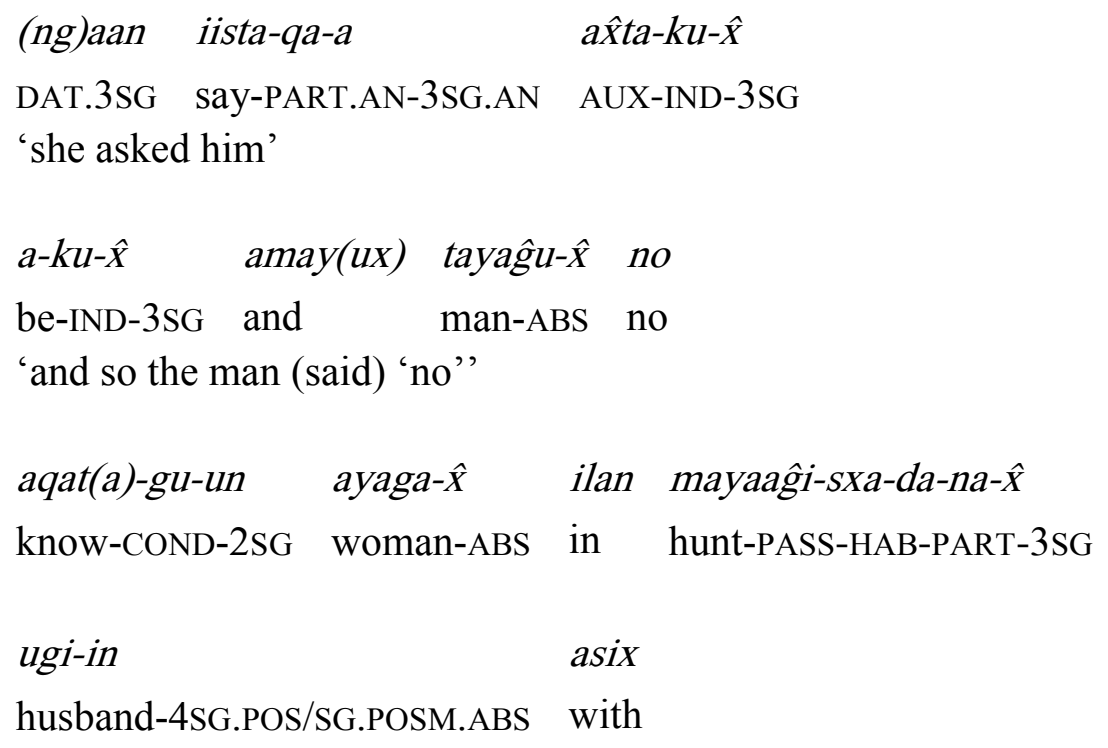

adan uya-agan mata-laka- $\hat{x}$

to go.toward-INTEN.3SG be.such.that-NEG.IND-3SG

'you know a wife should not go hunting (lit. to the ones that are hunted) with her husband' (M)

\section{(13) laavkaĝi-1(ix) amayux anaĝi-n ukux̂taasa-ang(an) \\ go.to.store-CONJ and thing-PL inspect-INTEN.1SG \\ 'I'm going to the store and I'm going to sightsee' (M)}

Amayux is interpreted as a discourse connector in example (12) because it links more than the immediately adjacent phrases or clauses, there is a switch in perspective, participant, etc., and the connection helps move the narrative along. However, this example could also be interpreted as a coordinate structure, with the coordinate elements showing equivalence at various linguistic levels (cf. Mauri 2008) of syntax (both are quotative constructions), semantics (question and answer pair), cognition (both are foregrounded) and pragmatics (the answer relates to the question). If so, coordination as a linking strategy may apply not only to lexical, phrasal, and clausal units, but also to discourse units in Unangam Tunuu; this seems possible but requires more study (cf. Fabricius-Hansen, et. al. 2005, who argue against automatically generalizing the application of coordination to discourse cross-linguistically, and Blühdorn 2008 who argues that coordination is not a discourse concept).

Ama and its derivatives also function as needed as disjunctives. ${ }^{7}$ Using ama in this way tends to underspecify the nature of the coordination, such that it could be interpreted as either conjunctive or disjunctive, and context is used for disambiguation. Ohori (2004:56-57) and Mauri (2008:181) suggest that when conjunction and disjunction are underdifferentiated, the marker derives its interpretation of disjunction from the presence of some notion of irrealis in the

\footnotetext{
${ }^{7}$ Bergsland (1994:59) writes that a common disjunctive coordinator in the Atkan dialect is amasxuu, which is a combination of the conjunctive ama and a disjunctive particle asxuи 'or' lit. 'if it is' (asxuи is related to Eastern aguun 'if it is').
} 
verb. This cannot be the only basis for such an interpretation in Unangam Tunuu, however, since conjunction is a possible reading in structures with unrealized situations. In example (14), the particle amayux can be used with disjunctive semantics, but it will probably be interpreted as disjunctive rather than conjunctive because of the use of ilakix 'either, (lit. one of two parts)' rather than because of the intentional verb mood:

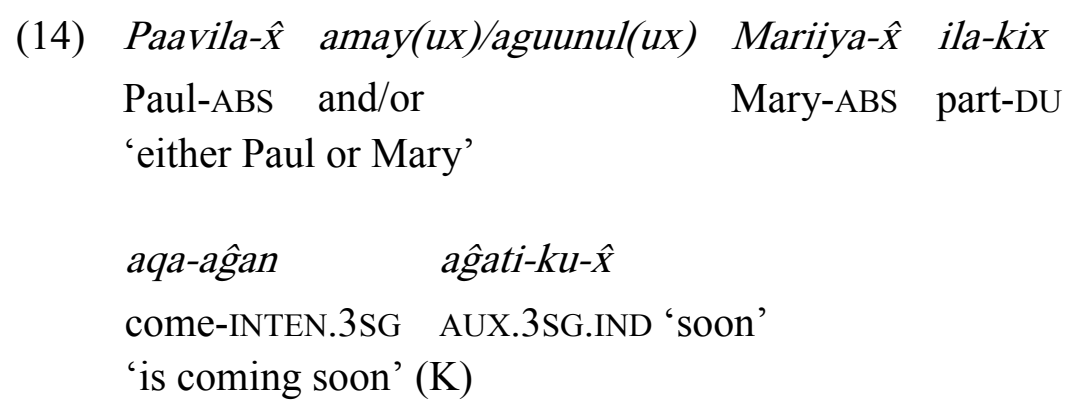

Finally, ama and its derivatives also on occasion function as adversatives as in example (15):

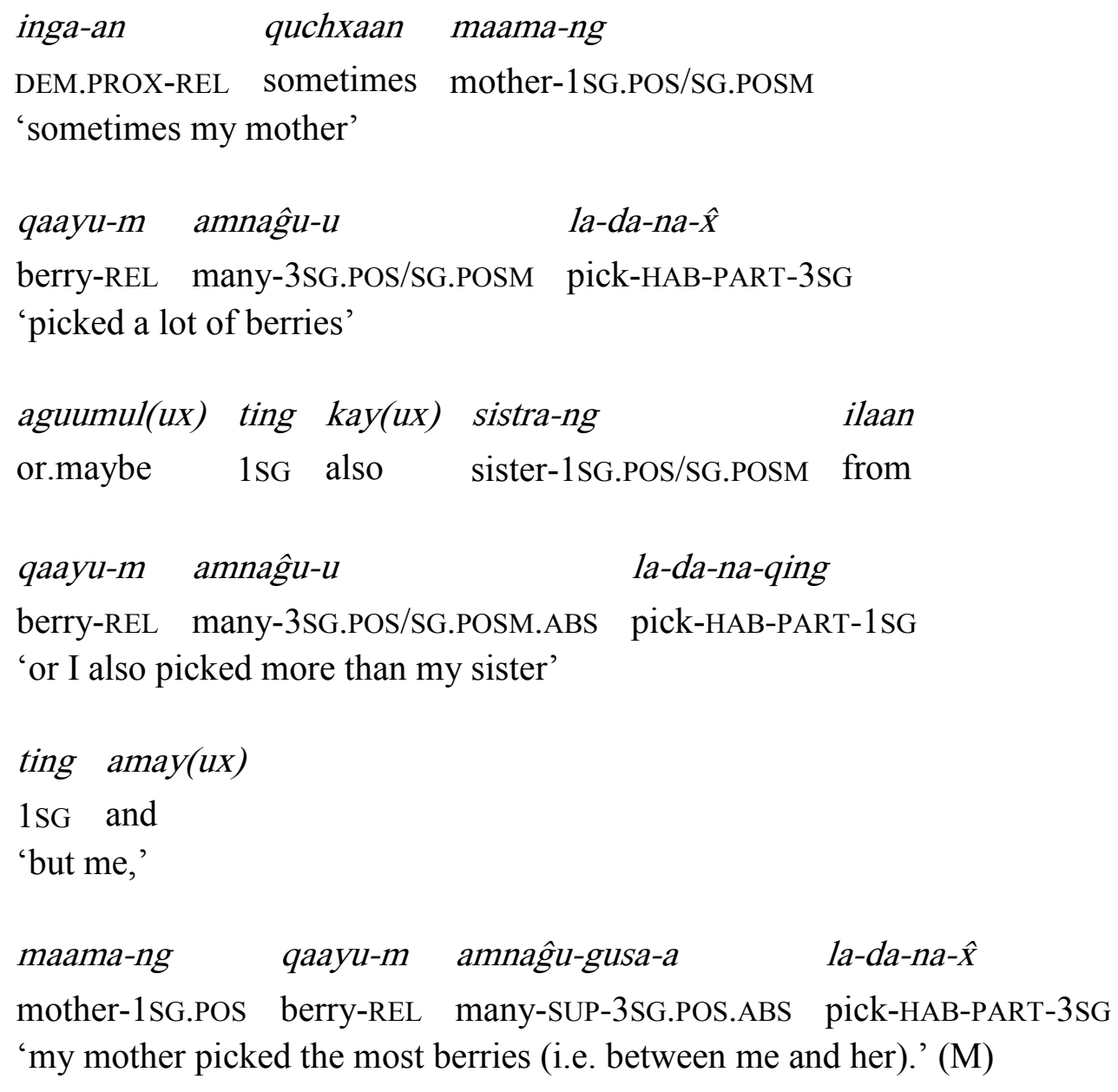

The particle amayux here is postposed to a preposed, focused element of the following clause: ting $\operatorname{amay}(u x), \ldots$ rather than $\operatorname{amay}(u x)$ ting...; postposition almost always signals some added 
emphasis, and it is frequently interpretable as adversative. In this example, the clause with amayux is in opposition to the immediately preceding clauses.

\subsection{The adverbial kayux}

The particle kayux 'also' is most commonly an adverbial, as illustrated in examples (16) and (17). As an adverbial, it has a certain freedom in its placement in the clause: it is found clause initially, clause finally, and after an element in a clause which is particularly emphasized. In example (16), kayux is clearly adverbial, following a conjoined clause with an ellided head and an overt marker of conjunction. The particle in example (17) is interpreted as an adverb rather than a conjunction because it can be and because that is its primary function. In addition, its placement after the first element of the second clause tends to reflect an adverbial usage, although not exclusively: both amayux and kayux can be postposed with conjunctive meaning (see example (18) below):

\begin{tabular}{|c|c|c|}
\hline sistra-ng & $q a-\hat{X}$ & 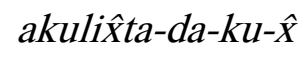 \\
\hline sister-1SG.POS/SG.POSM & fish-ABS & like-HAB-IND-3SG \\
\hline
\end{tabular}

$\operatorname{amay}($ ux $)$ ugi-i kayux

and husband-3SG.POS/SG.POSM.ABS too

'and her husband (does) too.' (EK)

\begin{tabular}{lll}
$\ldots u l u-\hat{X}$ & \multicolumn{1}{c}{ isila-ada- $0-\hat{X}$} & iti-lix \\
meat-ABS & cut.in.pieces-DIM-ZERO-ABS & make.into-CONJ \\
'...cutting the meat in small pieces,' &
\end{tabular}

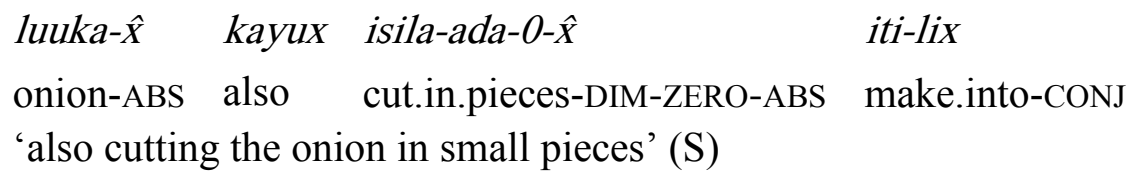

Example (17) is actually ambiguous, and kayux can be interpreted as a conjunction; this ambiguity may be leading to its grammaticization as a conjunctive coordinator, at least in the Eastern and Pribilovian dialects (Bergsland 1997:196 glosses it as 'also; E and also, and,' suggesting that it is not conjunctive in Atkan). In examples (18) and (19), kayux has conjunctive semantics. In the former, the clauses are sequential, and the particle kayux is postposed, which signals some added emphasis of the coordinated element; in the latter, kayux looks like a typical coordinating particle both in its placement and its semantics:

$\begin{array}{lll}\hat{x} u l u s t a a k a-m & \text { sanर̂xu- } u & \text { icha-lga-lix } \\ \text { fur.seal-REL } & \text { stomach-3SG.POS/SG.POSM.ABS } & \text { fill-PASS-CONJ } \\ \text { 'a fur seal's stomach is filled,' } & \end{array}$


sausage liid(a)-ta-lga-lix una-lga-da-qa- $\hat{x} \quad k a y(u x)$

sausage be.like-CAUS-PASS-CONJ cook-PASS-HAB-PART.AN-3SG and

'made into a sausage and it is cooked' (FP)

\begin{tabular}{|c|c|c|c|c|}
\hline ilaasa- $\hat{x}$ & kayux & anghagina- $\hat{x}$ & 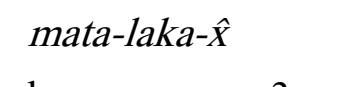 & inaqaadaam \\
\hline
\end{tabular}

As a conjunction, kayux is found at all structural levels, but it has a more restricted usage than amayux. For example, in lists and titles, it is postposed and adverbial, and expresses an afterthought rather than something integral to the list or title. Despite this, some speakers make more use of kayux than amayux as a conjunctive coordinator, preferring to use the latter as a discourse connector.

\subsection{The base $a$ -}

The base $a$ - 'to be' is at the root of a number of coordinating particles, most of which function as disjunctive coordinators. The most general is based on the conjunctive verb alix 'being.' As a conjunctive verb, alix functions as the copula in subordinate clauses, as in example (20):

$\begin{array}{lll}\text { chaaska- } \hat{X} \text { a-lix } & \text { aguunul(ux) } & \text { a-lakan } \\ \text { cup-ABS be-CONJ or } & \text { be-NEG.CONJ } \\ \text { 'is it a cup or not?' (F) } & \end{array}$

However, in the Eastern and Pribilof dialects (but not Atkan), it can function as a disjunctive coordinator, especially between noun phrases, as in example (21), and almost exclusively in questions:

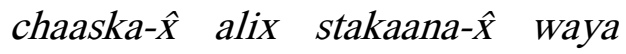

$$
\begin{aligned}
& \text { cup-ABS or glass-ABS this } \\
& \text { '(is) this a cup or a glass?' (F) }
\end{aligned}
$$

The use of alix in questions may be limited if alix is also used as a main verb in the same clause:

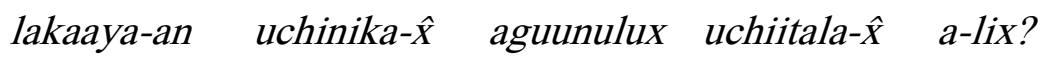
son-2SG.POS student-ABS or teacher-ABS be-CONJ
'is your son a student or a teacher?' (F)

Example (23) is potentially ambiguous: it is either an asyndetic disjunction with the verb alix or a syndetic disjunction with the particle alix: 


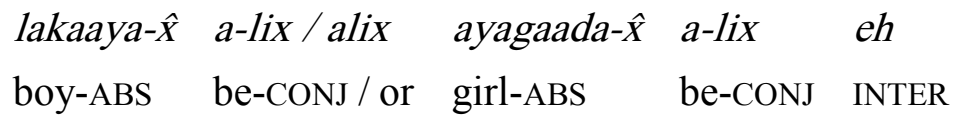

'is it a boy or a girl?' (M)

The particle alix is frequently followed by kayux 'also,' as in example (24):

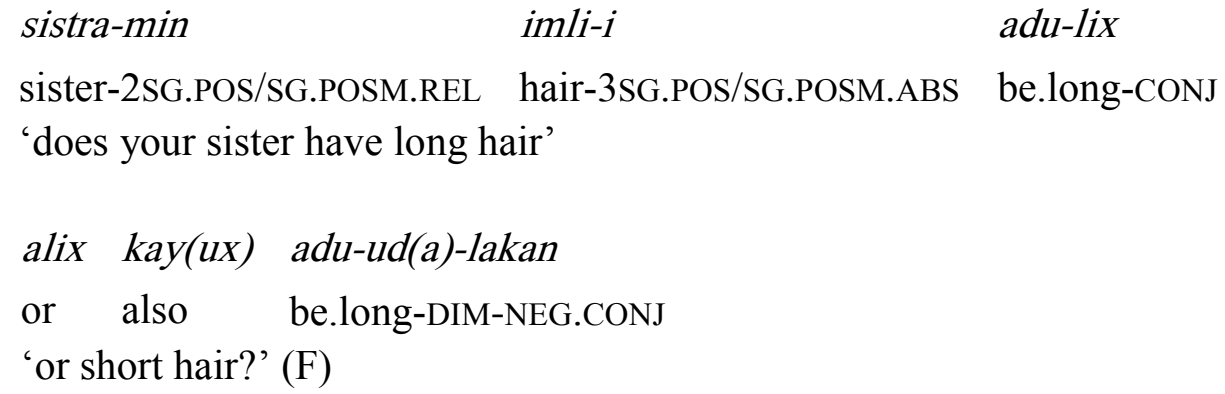

In combination with kayux 'also,' it can be used as a conjunctive coordinator, as in example (25). This usage is fairly widely used among speakers and may indicate some degree of emphasis. The combination alix kayux in both examples (24) and (25) results in a non-transparent meaning, suggesting that the combination has been lexicalized. As with amayux, the distinction between conjunction and disjunction is temporarily neutralized, and the meaning of the coordination relation is derived from context:

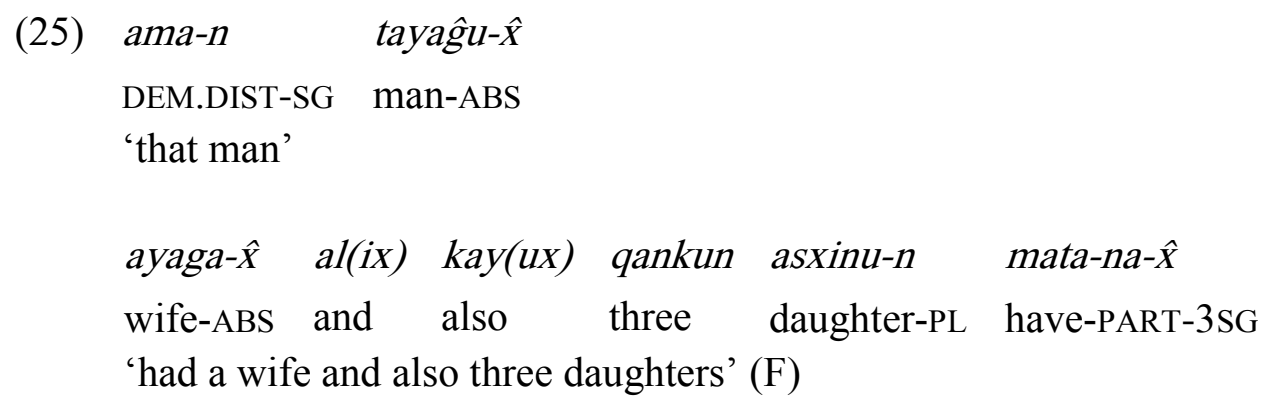

Bergsland (1994:1-2; 1997:340) states that clause initially, it can also function as an adversative coordinator; it is unclear if he means as a clause coordinator or discourse connective, however. While I have no examples of alix as an adversative clause coordinator, example (26) illustrates its use as an adversative discourse connective:

$$
\begin{array}{llll}
\text { alix } & \text { chitaaya-lix } & \text { aguumulux } & \text { alugi-0-txin } \\
\text { but } & \text { read-CONJ } & \text { or } & \text { write-ZERO-2SG }
\end{array}
$$

'but are you reading or writing?' (S)

Alix is more multifunctional, more general, and less lexicalized as a coordinator than the other disjunctive coordinators; however, it is not the most common. The base $a$ - 'to be' with the negative conditional mood, aguunulux 'if it is not' is used exclusively for disjunction and is in fact the most common disjunctive coordinator in the speech of the Pribilof Islanders, both in 
terms of its frequency of use and the number of speakers who make use of it. ${ }^{8} \mathrm{~A}$ common derivative form is the dubitative aguumulux 'if it might not be,' from a-gu-un-m-ulux 'be-COND3SG-DUB-NEG,' meaning 'or maybe' (cf. Bergsland 1997:195): ${ }^{9}$

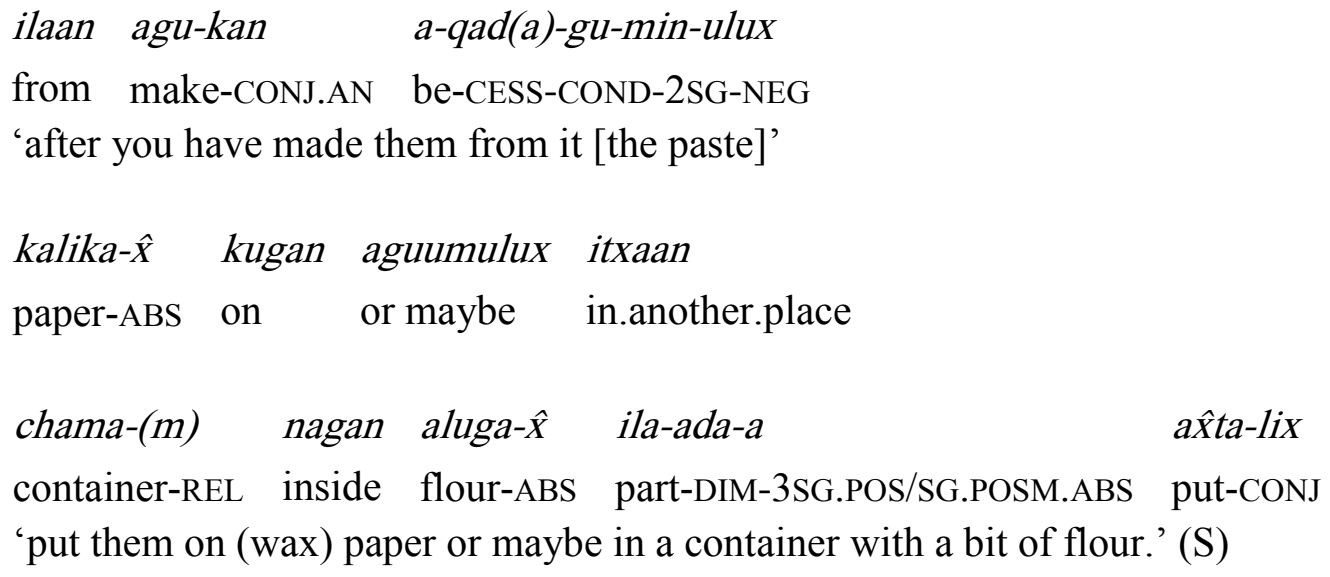

Both aguunulux and aguumulux can be used for trailing sentences (example 28) and both can be the final trailing element (whereas alix cannot be used in this way):

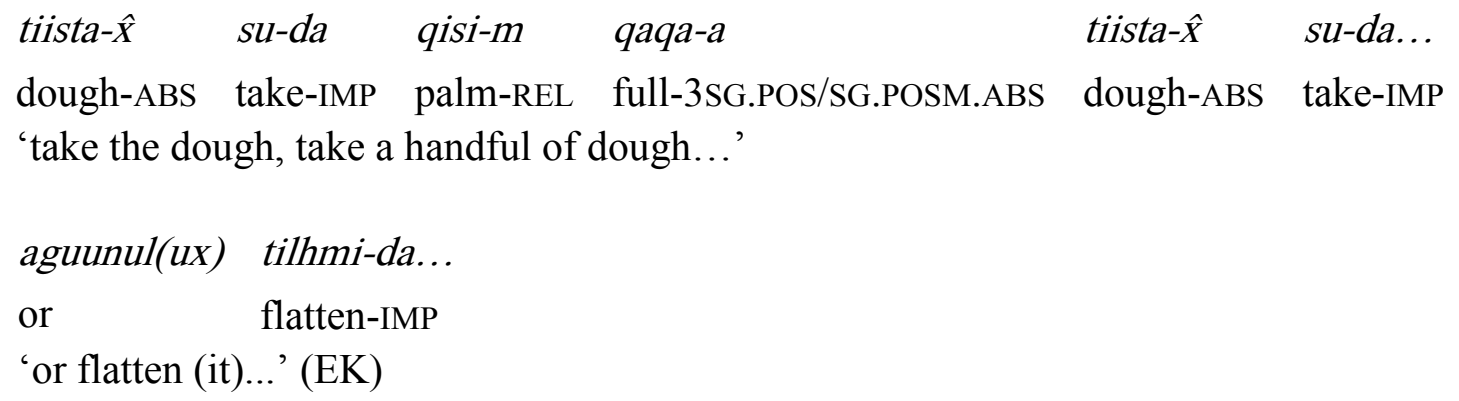

The negative conditional form results in a construction which is syntactically identical to the subordinate construction for the expression of disjunction described above, 'If not $\mathrm{X}$, Y;' however it is grammaticized in its coordinative function. The verb $a$ - 'to be' in other moods is not used for disjunction.

\subsection{1 asix 'with, together with, also'}

Finally, the base $a$ - also contributes a particle asix 'with, together with, also;' Bergsland (1992:101) sees asix as a petrified conjunctive mood of at-, ultimately from $a$ - $t$ - 'be-CAUS-' 'to bring about.' It is one of a little collection of comitative constructions in Unangam Tunuu which differ broadly in their applications. For example, asix is a general comitative, while agiitalix 'together with,' tends to be used with humans. Both are morphologically conjunctive mood

\footnotetext{
${ }^{8}$ Bergsland, 1994:1 also lists the positive form, aguun 'if it is,' for the Atkan dialect; this is not used in the Pribilofs. ${ }^{9}$ Other dialects have slight variations of this form as well as other derivations. Atkan asxuu(nulax) instead of aguunulux as well as the fused particle атазхии (Bergsland, 1997:196), see footnote 3; and Eastern (but not attested in the Pribilofs to my knowledge) aasxuunulux 'if it is not' from a-asa-guun-ulux 'be-APPLICATIVE-3SG.COND-NEG' (ibid.).
} 
forms, but whereas agiitalix is more clearly verbal, as in example (29), asix is more grammaticized as a particle (cf. example 12), although it can still function as a conjunctive verb. It can in some cases be used as a conjunctive coordinator, as in example (29).

braata-ning imgấ-ku-ngin

brother-1SG.POS/PL.POSM go.deep.sea.fishing-IND-3PL.AN

'when my brothers went deep sea fishing,'

agiita-lix ayuxta-lix

be.together.with-CONJ go.out.in.boat-CONJ

'I used to go out in the boat together with (them)'

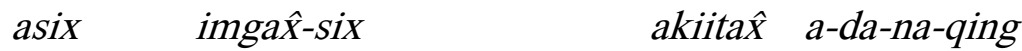

and/with go.deep.sea.fishing-CONJ as.well be-HAB-PART-1SG

'and go deep sea fishing as well' (OM-Eastern)

There is a certain ambiguity in the use of this particle, and it seems to be interpretable as a conjunctive marker by some Pribilovians, while still obviously retaining comitative semantics. We see evidence of this in the different possibilities for subject-verb agreement in examples (30) and (31), both from one and the same speaker:

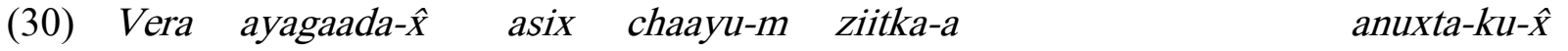

Vera daughter-ABS with tea-REL weak-3SG.POS/SG.POSM.ABS want-IND-3SG 'Vera, with her daughter, wants some weak tea' (= 'Vera and her daughter want weak tea') (F)

(31) Vera ayagaada-n asix chaayu-m ziitka-ngin anuxta-ku-n Vera daughter-PL with/and tea-REL weak-3(PL)POS/(PL)POSM want-IND-3PL 'Vera, with her daughters, want weak teas' = 'Vera and her daughters want (their) weak teas' (F)

In example (30), asix seems clearly to be used as a comitative (whether it is analyzed as a particle or a conjunctive verb). Example (31), however, suggests some level of coordination, judging from the plural verb agreement. Unangax agreement rules are far from simple, and plurality is one of the complicating factors in subject-verb agreement. In noncoordinated constructions, a verb may have plural agreement despite a singular subject if a plural argument or possessor is unexpressed; however this is not the case in example (31). Coordinated constructions affect subject-verb agreement: a verb may be inflected for plural if the second coordinated element is plural, which would explain the inflection in example (31). These examples, however, are not uniformly accepted by all speakers, and the status of asix appears to be in flux. In any event, it is not commonly used in a conjunctive capacity, and some speakers do not use it at all (even as a comitative, judging it to be older language). 
Bergsland specifically lists the fused form amasix as a conjunctive coordinator in both Atkan and Eastern dialects, rather than asix (1997:195) In the Pribilovian materials I have collected, amasix is used as a discourse connector in narratives, as in example (32), but not as a coordinator:

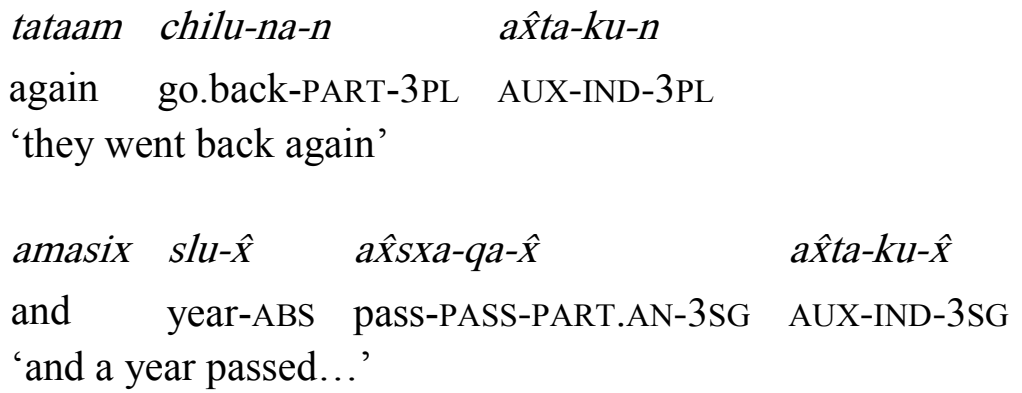

\subsubsection{The adversative $\operatorname{ta} \hat{x}$, taga $(\hat{x})$}

The particle tâx, taga $(\hat{X})$ is a discourse particle expressing either sequentiality ('now,' or 'so,' see example (37)) or an interjection ('well!' or 'enough!'). ${ }^{10}$ It also serves as an adversative coordinator, providing the most common way of expressing adversative semantics in Pribilof Islands Unangam Tunuu, as in example (38):

\begin{tabular}{|c|c|}
\hline Ama-n $\quad$ aluga-a & nagan âxta-qad(a)-gu-min-ulux \\
\hline $\begin{array}{l}\text { DEM.DIST-SG flour-3SG.POS/SG.POSM.ABS } \\
\text { 'After you place (them) inside the flour' }\end{array}$ & inside put-CESS-COND-2SG-NEG \\
\hline 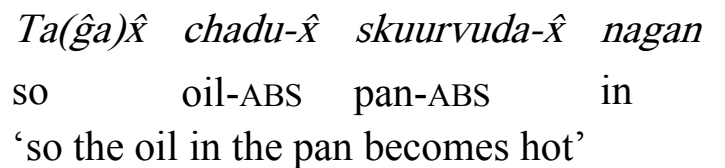 & $\begin{array}{l}\text { txin chinglit- } \\
\text { self become.hot- }\end{array}$ \\
\hline $\begin{array}{l}\text { ama-kun miichi-n agu-na-txin } \\
\text { DEM.DIST-PL ball-PL make-PART-2SG } \\
\text { 'those (meat)balls you made,' }\end{array}$ & \\
\hline $\begin{array}{l}\text { ama- } n \quad c h a d u-u \\
\text { DEM.DIST-SG oil-3SG.POS/SG.POSM.ABS } \\
\text { 'cook them in that oil' }(\mathrm{S})\end{array}$ & $\begin{array}{ll}\text { nagan } & \text { una-kan } \\
\text { inside } & \text { cook-CONJ.SG.AN }\end{array}$ \\
\hline
\end{tabular}

\footnotetext{
${ }^{10}$ Bergsland (1994:383) lists this as tâx, taĝa; my consultants also gave the form taĝâ.
} 


$$
\begin{array}{ll}
\hat{x} u l u s t a a k a-X & \text { anutaasa-qa-ngin } \\
\text { fur.seal-DU } & \text { think-PART.AN-3PL.AN }
\end{array}
$$

$$
\begin{array}{lllll}
\operatorname{tag} a(\hat{X}) & \text { aalax } & \text { isuga-X } & \text { a-na-X } & \text { a } \hat{x} \operatorname{ta}-k u-\hat{X} \\
\text { but } & \text { two } & \text { hair.seal-DU } & \text { be-PART-DU } & \text { AUX-IND-3SG } \\
\text { 'they thought they were two fur seals, but they were two hair seals' (M) }
\end{array}
$$

\subsection{The causative malix and other minor, possibly coordinating particles}

Some languages are said to have causal coordinators (Haspelmath 2007:2), which may seem counterintuitive given a definition of coordination which includes the syntactic and semantic equivalence of the coordinated items. Various tests suggest at least some syntactic reasons for positing causal coordinators (e.g. Dik 1968:291, regarding English for).

That the three types of coordinating structures traditionally proposed are conjunction, disjunction, and adversity may in part be because studies of coordination historically were grounded in the study of logic (Rousseau 2007:30; cf also Payne 1985:3), and the logical relations and, or, and not which are characterized as symmetric, as opposed to the asymmetric logical relation if, which gives rise to a number of subordinate forms. However, language is not bound by logic, and there is no a priori reason to assume that linguistic coordination consists only of these three types. Furthermore, there are differences in the requirements of coordinate constructions in logic and natural language (e.g. conjunction is not always semantically symmetrical $)^{11}$. It is true that typologically, conjunction, disjunction, and adversity are fairly common in languages with coordinate constructions, while other possibly coordinate structures are rarer, less prototypical, and share characteristics of subordinate structures. For example, causal coordination is semantically asymmetrical and may have a much more restricted range of application than the more prototypical forms of coordination. Nevertheless, languages do have particles which coordinate clauses expressing semantic implication (e.g. German doch, French or, pourtant, etc. Rousseau 2007:34).

In Unangam Tunuu, there is a causative particle malix 'doing so, because' (Bergsland 1997:243, calls it a subordinating particle). Unlike most coordinators, it is typically postposed; but it most often links clauses which are structurally parallel, such as two indicative clauses, often with an enclitic in the causative clause, and there are other more clearly subordinate ways of indicating causation, using dependent verb moods: ${ }^{12}$

\footnotetext{
${ }^{11}$ Despite a general insistence on symmetry in coordinate structures, there is not infrequently an inescapable semantic asymmetry arising from the linear sequence of the coordinated terms. It is hard to maintain that there is no semantic difference between examples a and $b$ :

a. 'The dwarfs (sic) were ugly but kind' (Haspelmath 2007:2)

b. 'The dwarves were kind but ugly.'

${ }^{12}$ causation can be signaled with juxtaposition just as the other forms of coordination can, without any sign of subordination, e.g.

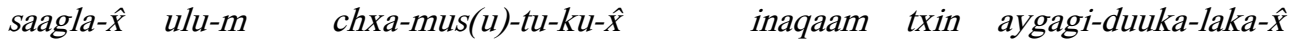

dog-ABS meat-REL steal-perhaps-AUG-IND-3SG self.4SG self walk-FUT-NEG.IND-3SG

'The dog must have stolen the meat, it can't go away by itself.' (M)
} 

qigusi-ning
chumnugi-ku-n
tooth-1SG.PL.POS/PL.POSM yellow-IND-3.PL
'my teeth are yellow'

\section{kuri-d(a)-na-qing-aan malix}

smoke-HAB-PART-1SG-ENCL.SG because

'because I used to smoke' (M)

Furthermore, malix is a discourse connector similar to amayux for indicating continuation of an action and frequently can be translated as 'and' (Bergsland 1997:339, although this probably refers to the discourse sense 'and then'). Bergsland (1997:245) also briefly mentions the use of the auxiliary use of alix 'to be' as some kind of clause linker, and speakers frequently use the indicative form $a k u \hat{x}$ 'he, she, it is' clause initially as a clause connector, with sequential and possibly causal semantics. ${ }^{13}$

Any one of these may be investigated for their coordinative effects, and all of them are relatively common in conversational speech. I mention them here, but will not further refer to them at this time.

\section{Usage of Coordinators in Different Types of Coordinate Structures}

Conjunctive and disjunctive coordination allow all syntactic levels to be coordinated with particles (NP and NP, VP and VP, AP and AP, etc.), whereas adversative coordination tends to be used to link clauses and predicates. All types are found in a wide variety of contexts (narratives, conversation, lists, titles, etc.). Each type of coordination can be expressed using one of a number of possible particles (in addition to clause-chaining and subordination strategies for linking clauses with similar semantics), and there is some functional overlap between the more general particles (amayux is used for all three coordinative functions, and alix and alix kayux for two of the three), although, as we have seen, the particles are not all used by all speakers, nor do they have the same distribution of use. In addition, there are differences in particle use in the expression of various constructions involving coordination.

\subsection{Conjunction}

Of the three types of coordination, by far the most common and the most generalized is conjunctive coordination. There are some differences between the semantic types of conjunction. Thus, simultaneous and atemporal clauses are frequently linked via conjunctive coordination, as in, respectively, examples (40) and (6), repeated below as example (41) (see also example (13)):

$$
\begin{array}{lll}
\operatorname{aygax}-s(i x) & \operatorname{amay}(u x) & \text { unuugi-itu-d(a)-ku-qing } \\
\text { walk-CONJ } & \text { and } & \text { sing-want-HAB-IND-1SG }
\end{array}
$$

'I want (like) to walk and sing (at the same time)' (= 'I like to sing while I walk, I walk

\footnotetext{
${ }^{13} A k u \hat{x}$ 'he, she, it is' in this usage is not to be confused with akugaan 'if, when he, she, it is,' from aku- $\hat{x}-n g a a n$ 'be-3SG.IND-ENCL.'
} 
and sing at the same time') (K)

Further, simultaneous and atemporal conjunction can be expressed via non-parallel syntactic structures, with one clause in the conjunctive mood and the second in a superordinate mood as in examples (40) and (41), or parallel structures, with both clauses in the same mood, as in example (42):
awa-m (ng)aan uyaam a-qal(i)-ku-qing
work-REL DAT.3SG today be-begin-IND-1SG
'I'm going to work today'

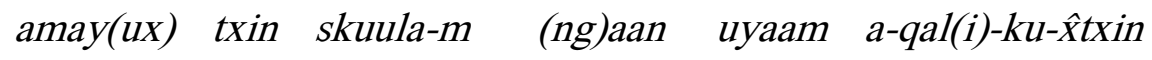
And 2SG school-REL DAT.3SG today be-begin-IND-2SG
'and you are going to school today' (K)

Sequential clauses, however, are invariably chained, without a coordinating particle, as in example (43) (see also example (2)), and sometimes the sequential nature can be made explicit with the use of the cessative postbase -qada- or its independent form, aqadagu- 'after that' (with the appropriate person ending and the negative enclitic; examples (44-45)).

$\begin{array}{lll}\text { anqax̂ta-m } & \text { anaĝi-ngin } & \text { su-lix } \\ \text { hunting-REL } & \text { thing-3(PL)POS/(PL)POSM } & \text { take-CONJ }\end{array}$

'taking your hunting gear,'

agal(i)kii(mi)ng aygagi-d(a)

after.ABL walk-IMP

'follow me' = 'Take your hunting gear and follow me.' $(\mathrm{K})$

(44)
ilaasa-ning
guusti-q(a)da-gu-ung-ul(ux)
relative ${ }^{14}-1$ SG.POS/PL.POSM visit-CESS-COND-1SG-NEG
'after I have visited my relatives'

\footnotetext{
${ }^{14}$ ilaasa- means both 'friend' and 'relative,' and different speakers may have different preferences regarding the scope of the meaning of the word in their idiolects. The glosses here reflect the meaning of the particular sentence given by the speaker.
} 
taaya-duu-ku-q(ing) ta(ga) $\hat{x} \quad$ liisna- $\hat{x} \quad$ aki-duuka-l(a)ka-qing

shop-FUT-IND-1SG but not.too.much-ABS buy-FUT-NEG-1SG

'I'll go shopping, but I won't buy very much' (M)

(45)

ilaasa-ning guusti-1(ix)

relative-1SG.POS/PL.POSM visit- CONJ

'visiting my family, after that shopping,'

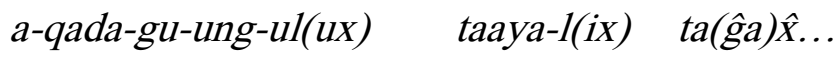

be- CESS-COND-1SG-NEG shop- CONJ but

but...' (M)

To express emphatic conjunction (e.g. 'both...and'), there are several options, including the postposing of a conjunctive particle (example (18)) and the use of two-word structures (very obviously from $u s u$ - 'all') and ila- 'part'); amayux with $u s u$ - appropriately inflected for dual or plural can also be found for conjunction of more than two items, as in example (46):
bingo $\operatorname{amay}(u x)$ âxa-O- $\hat{x}$
usu-kix malga-agan
angal(i)kinga-an
bingo and
dance-ZERO-ABS all-DU
exist-INTEN.3SG evening-ABL
'there will be both bingo and dancing tonight' (M)

The conjunction amayux can be repeated for the same effect, although in this case, it precedes the conjuncts:
lakaaya-an
$\operatorname{amay}(u x)$ qaya-1(ix)
son-2SG.POS/SG.POSM.ABS and
high-CONJ

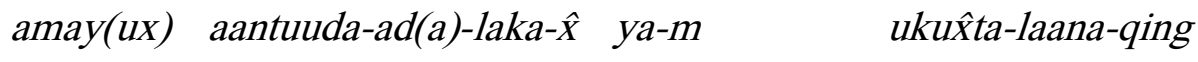
And thick-DIM-NEG-3SG yesterday-REL see-RECENT.PAST-1SG
'your son is the tall thin man I saw yesterday' $(\mathrm{K})$

The equivalent of the English neither-nor construction (which logically, is a conjunction meaning 'not... and not') is effected with a single conjunction amayux and negative inflection on the verb:
inga-kun
lakaaya-n am
$\operatorname{amay}(u x)$
inga- $n$
ayagaada $-\hat{X}$
DEM.PROX-PL boy-PL and
DEM.PROX-SG girl-ABS
'Neither those boys nor that girl' 
$\operatorname{amaan}(u)-d u u k(a)-l a k a-\hat{X}$

go.over.there-FUT-NEG.IND-3SG

'will go there'

\subsection{Disjunction}

Disjunction in Unangam Tunuu is relatively common, and there are more choices of disjunctive constructions than with conjunction and more specific semantic and syntactic differences among the different particles.

Disjunction in Unangam Tunuu may not be neatly categorized by the opposition between only two types of disjunction. Three types of distinctions are made, between 1) a structure in which the speaker asks for information, the listener is not being asked to make a choice between two items but rather to inform the speaker, and the effect is similar to exclusive disjunction; 2) a structure which requires a choice of the listener, which may be either choice-based or exclusive disjunction; and 3) a syntactically disjunctive structure which has non-disjunctive semantics, often similar to a polar question or an inclusive disjunction. The noticeable split in marking these structures is not between types 1-2 and 3, as one might have expected, but between types 1 and 2-3.

Type 1 disjunction is most frequently expressed with the disjunctive coordinator aguunulux. In example 6 below; the question presupposes that 'your son' lives in one of the two places, and the answer will be one or the other place (as opposed to 'yes' or 'no'):
lakaaya-an
Anchorage-am ilan aguunul(ux) Seattle-am il(ix $)^{15}$
tanagi-lix?
son-2SG.POS/SG.POSM.ABS Anchorage-REL in or
Seattle-REL in
live-CONJ
'does your son live in Anchorage or in Seattle?' (K)

The lack of choice in this type of disjunction explains the avoidance of aguumulux 'or maybe' (its use in example (49) results in the question being interpreted as polar).

Although there is a clear preference for its use in types 2-3 disjunction, alix can sometimes indicate an exclusive or type 1 disjunction in questions; whether or not it can do so in statements depends on the speaker's judgment of the irrealis or realis status of the verb. In example (50) below, there are two possible interpretations: 'is either Paul or Gregory going to talk?' (a polar question, type 3 ) or 'Is Paul or is Gregory going to talk?' (a type 1 question); some speakers do not, however, permit the equivalent indicative construction, as in example (51); parentheses around the * indicate that some speakers do not permit this), while others do, but only in future indeterminate statements, as in example (52):

\section{(50)

\begin{tabular}{|c|c|c|}
\hline Paavila- $\hat{X}$ alix & 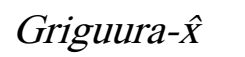 & tunux̂ta-duuka-lix? \\
\hline Paul-ABS or & Gregory-ABS & talk-FUT-CONJ \\
\hline
\end{tabular}

${ }^{15}$ The form ilix for ilan 'in' is commonly heard in the speech of the Pribilof Islanders. 


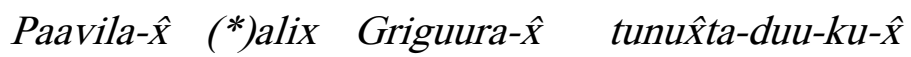

Paul-ABS or Gregory-ABS talk-FUT-IND-3SG

'Paul or Gregory is going to talk' $\left(\mathrm{F},{ }^{*} \mathrm{~S}\right)$

\begin{tabular}{|c|c|c|}
\hline 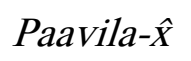 & aguunul(ux)/*alix & 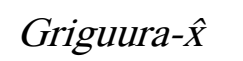 \\
\hline Paul-ABS & or & Gregory-ABS \\
\hline
\end{tabular}

Choice-based disjunction (type 2, example (53)) is generally indicated with aguumulux 'or maybe' or alix 'or.' Some speakers have a clear preference for one of the two disjunctive coordinators, while others use both, with different but overlapping sets of structure possibilities. For example, alix is almost exclusively used in questions, whereas aguumulux is found in either questions or statements; and some speakers simply use aguumulux as their disjunctive particle of choice for types 2 and 3 .
axa-amin
alix muuvi-imin ${ }^{16}$
dance-2SG.INTEN or movie-2SG.INTEN
'are you going to dance or go to a movie?' (S)

The choice-based disjunctive coordinate structure with aguumulux is used pragmatically for indirectly showing disagreement with someone, and it is also one way of expressing something politely. In both cases, this is probably due to the combination of a disjunctive structure with the dubitative morpheme $-m$-: the expression of doubt allows the listener to make a choice in his or her response, but it also allows the speaker to distance him- or herself from either the actual statement or the response.

Inclusive or simple disjunction (type 3, examples (54) and (55) interpreted as polar questions) can be expressed with either aguumulux or alix, although the latter is most common. It tends to be used in general situations, which may explain the non-disjunctive nature of the construction.

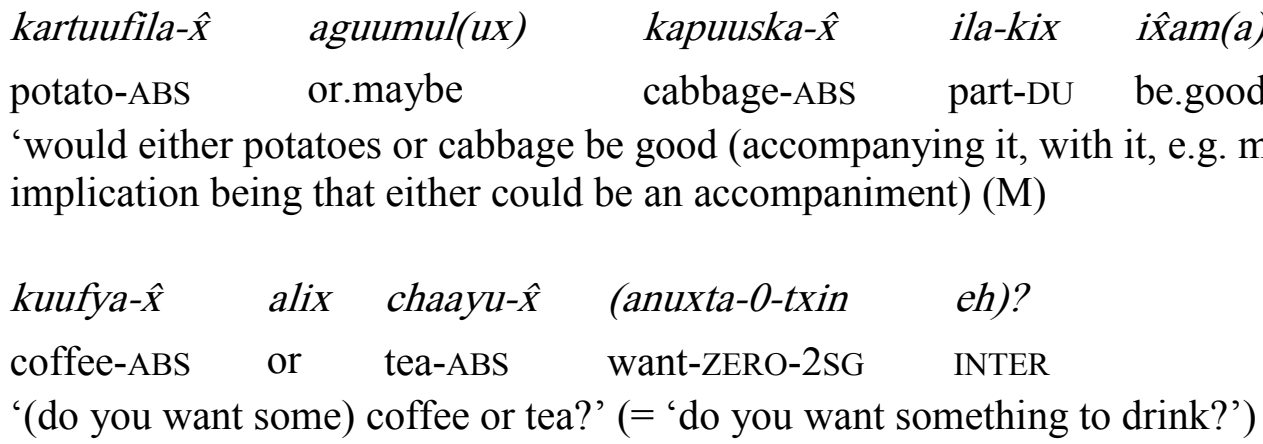

\footnotetext{
${ }^{16}$ The intentional verb mood frequently takes an auxiliary; however, especially in $1^{\text {st }}$ and $2^{\text {nd }}$ person forms, the auxiliary is just as frequently omitted.
} 
Disjunction can be more emphatically expressed with a two-word structure; the second word, from ila- 'part,' is postposed to the second disjunct (example (54) and example (56)):

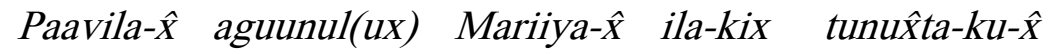

$$
\begin{aligned}
& \text { Paul-ABS or Mary-ABS part-DU speak-IND-3SG } \\
& \text { 'either Paul or Mary is speaking' }(\mathrm{K})
\end{aligned}
$$

\subsection{Adversative coordination}

Finally, although adversative coordination is the simplest in terms of the options available, it also shows some peculiarites of usage. The adversative particle taga $(\hat{x})$ is used for all three types of adversative relations described by Haspelmath (2004, 2007) and Mauri (2008). However, oppositive coordination, as in example (57) can also be indicated with the conjunctive coordinator amayux, as in example (58). This supports Mauri's (2008:131) observation that oppositive adversitive coordination and atemporal conjunction are often marked the same way (i.e. with the atemporal conjunction):

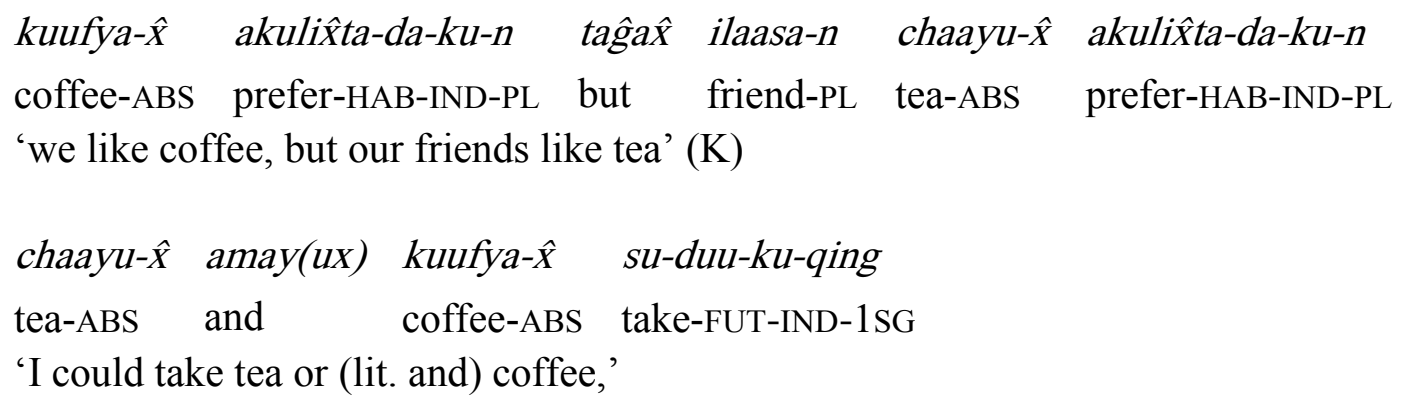

$\begin{array}{llll}\operatorname{amay}(\mathrm{ux}) & \text { taanga-m } & \text { qingana-a } & \text { kuugulux } \\ \text { and } & \text { water-REL } & \text { cold-3SG.POS/SG.POSM.ABS } & \text { no } \\ \text { 'but not cold water' }(\mathrm{S}) & \end{array}$

Oppositive and corrective structures appear to require parallel structures, as in examples (57) and (59) respectively, although this requires more investigation; in example (59), there are two superordinate moods. The counterexpectative can include nonparallel structures, as in example (60):

(59) $\hat{x} u l u s t a a k a-X$ anutaasa-qa-ngin

fur.seal-DU think-PART.AN-3PL.AN

'they thought they were two fur seals,'

$\begin{array}{lllll}\operatorname{tag} a(\hat{x}) & \text { aalax } & \text { isuga- } x & a-n a-X & a \hat{x} t a-k u-\hat{x} \\ \text { but } & \text { two } & \text { hair.seal-DU } & \text { be-PART-DU } & \text { AUX-IND-3SG } \\ \text { 'but they were two hair seals' (M) } & \end{array}$


(60)
Txin achan anguna-lix
2SG just big-CONJ
'you're so big'
taĝẩ ada-ada-an
anguna-ad(a)-laka- $\hat{X}$
but father-DIM-2SG.POS/SG.POSM.ABS
big-DIM-NEG.IND-3SG
'but your father is so small' $(\mathrm{K})$

\section{Effects of Coordination on The Syntax}

The coordination of two or more elements has significant syntactic effects on the larger construction of which the coordinated structure is a part. Thus, coordination affects the use of independent subject pronouns in a clause; the person and number agreement of the coordinated elements of a phrasal subject with the corresponding verb; and the expression of possession on the elements of a coordinated phrase. In addition, coordination can result in the use of ellipsis in clausal constructions, and the level of complexity of the phrases or clauses being combined may affect the choice of coordination or embedding as a strategy for clause construction.

Independent pronouns are primarily used as objects; as subjects, they are usually cliticized on the verb. However, at least in Eastern Unangam Tunuu, independent pronouns are used in any environment which changes the basic clause structure: they can be used to indicate emphasis of the subject or possessor, and they are used in elliptical structures (e.g. example (71)) and in conjunctive and disjunctive noun phrases (example (7), and example (61); see also Bergsland, 1997:57-58):

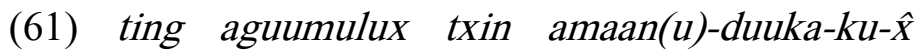 \\ $1 \mathrm{SG}$ or 2SG go.over.there-FUT-IND-3SG \\ 'you or I will go there' (M)}

Person and plural agreement are also affected by coordination: the verb tends to agree with the second conjoined or disjoined element in number, as in examples (62) and (63), but 3SG inflection on the verb is a common default form, as in example (64): the more complex the construction, the more likely the use of $3 \mathrm{SG}$ inflection on the verb. Conjunction involving $1^{\text {st }}$ or $2^{\text {nd }}$ person pronouns entails 3SG verb inflection (example (61)). Example (48), repeated as example (62) below, and example (63) are equally valid with aguumulux:

$\begin{aligned} & \text { inga-kun lakaaya-n amay }(u) x \\ & \text { inga-n } n\end{aligned}$
$\begin{aligned} & \text { DEM.PROX-PL boy-PL and } \\ & \text { 'neither those boys nor that girl' }\end{aligned}$
$\begin{aligned} & \text { amaan(u)-duuk(a)-laka- } \hat{X} \\ & \text { go.over.there-FUT-NEG.IND-3SG } \\ & \text { 'will go there' (M) }\end{aligned}$




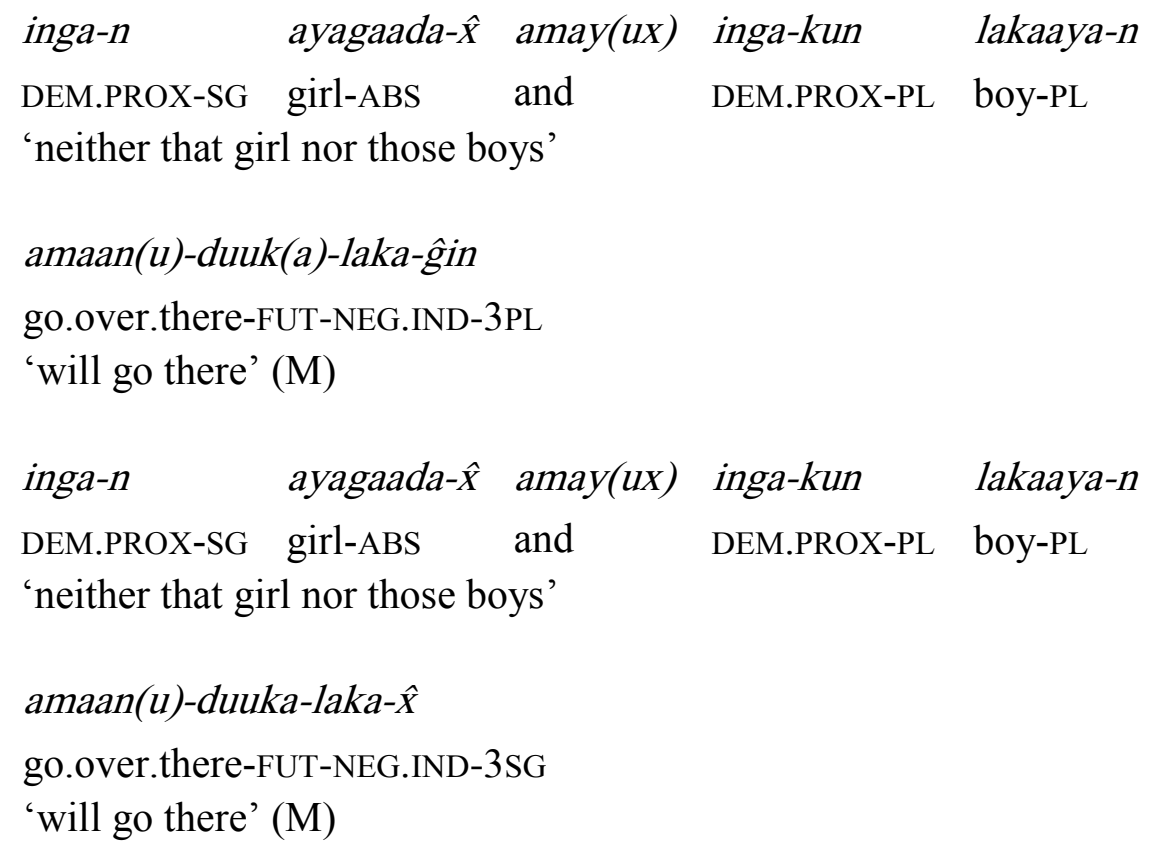

It is tempting to see these agreement patterns as the result of the original $3 \mathrm{SG}$ verb forms becoming grammaticized as coordinating particles, e.g. alix 'it being', or aguunulux 'if it is not;' the syntax would then reflect the older chaining structure, but the semantics would reflect coordination rather than chaining. However, this does not explain the same agreement patterns with amayux.

Some variation in agreement is permitted in coordinated possessive and adjective phrases, such that the first coordinated term may or may not require relative marking, and likewise the verb may or may not show plural agreement. This variation is present within the speech of individual speakers, as in examples (65) and (66):

$\begin{array}{lll}\text { braata-an } & \text { aguumulux } & \text { sistra-m(in })^{17} \\ \text { brother-2SG.POS/SG.POSM.ABS } & \text { or.maybe } & \text { sister-2SG.POS/SG.POSM.REL }\end{array}$

ula-a uxta-duuka-O-txin?

house-3SG.POS/SG.POSM go.to-FUT-ZERO-2SG

'are you going to your brother's or your sister's house?' (S)

\footnotetext{
${ }^{17}$ The inflection on sistram(in) ulaa is unclear, in part because either sistram ulaa 'sister's house' and sistramin ulaa 'your sister's house' would be acceptable constructions in the given context; personal possessive marking is not obligatory and is frequently absent in phrases with family relationships.
} 
braata-min aguumulux sistra-min

brother-2SG.POS/SG.POSM.REL or.maybe sister-2SG.POS/SG.POSM.REL

ula-a uxta-duuka-0-txin?

house-3SG.POS/SG.POSM.ABS go.to-FUT-ZERO-2SG

'are you going to your brother's or your sister's house?' (S)

Inflection of coordinated phrases with modifiers may be affected by changes in the construction of phrases. In Unangam Tunuu, modifiers generally follow the head, as in example (67); however, speakers from the Pribilofs often allow preposing of the modifier, in which case the phrase is not a possessive construction, and the modifier takes simple (absolutive) inflection, as in example (68). In coordinated phrases of this type, singular absolutive inflection of the modifier is retained, as in example (69):

braata-ng kinguuĝti-i

brother-1SG.POS/SG.POSM younger-3SG.POS/SG.POSM.ABS

'my younger brother.'

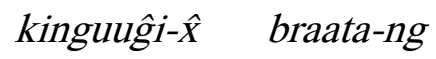

younger-ABS brother-1SG.POS/SG.POSM

'my younger brother'

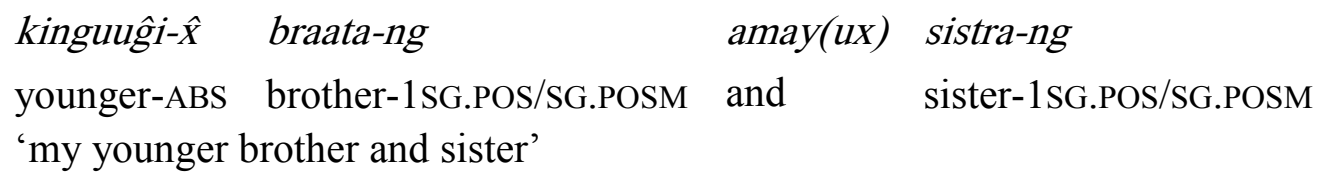

Ellipsis of verbs and oblique arguments in clauses with coordinated structures is allowed (there are no examples of ellipsis of nominals in my data), whether they are part of the coordination or not, with various strategies for recovering ellided information. Thus, in example (70), the verb, probably something like anuxta-0-txin 'want-ZERO-2SG' 'do you want?' is elilded (and therefore so is the pronominal trace of the subject); in example (71), the verb uya-angan 'get-INTEN.1SG' = 'I will get' is ellided, the only trace of it being the overt pronoun ting '1SG;' and in example (72), a filler verb is used; and in example (73), the verb and the postpositional phrase are replaced by the particle kuugu(lux) 'no,' while the object is retained:

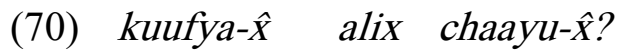

coffee-ABS or tea-ABS

'(do you want) coffee or tea?'

kuufya- $\hat{x} \quad$ uya-amin $\quad$ eh? aguunul(ux)/aguumul(ux) ting?

coffee-ABS get-INTEN.2SG eh? or/or.maybe 1SG

'are you going to get the coffee? or shall I?' (K) 
ix̂am(a)na-lix alix ma-lakan?

be.good-CONJ or do-NEG.CONJ

'is it good or not (good)?'

limuuna- $\hat{X}$ chaayum ilix chayu-utu-d(a)-ku-qing, $\quad($ taga $(\hat{x}))$ muluka- $\hat{x} \quad$ kuugu. lemon-ABS tea-REL in drink.tea-want-HAB-IND-1SG but milk-ABS no 'I usually drink tea (with) lemon in the tea, but not (with) milk' (S)

It is usually the second of two clauses which will undergo ellipsis; however, in example (74) (elicited to determine whether or not the English construction 'either I'm ... or he/she's ...' is possible in Unangam Tunuu: in general, it is not), the verb is ellided in the first clause (amayux is an adversative particle in this example): ${ }^{18}$

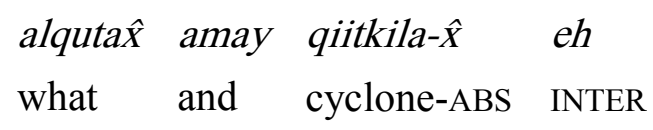

'but what (is that), thunder,'

aguumul(ux)/alix sanxu-un

or.maybe/or (M)

Finally, the more complex the structure, the more likely there is to be a modification of preferred strategy, whether this results in the use of coordination rather than subordination, or in the restructuring and ellipsis of a coordinated structure. In example (75), the otherwise preferred subordinated structure is replaced by a coordinated structure to avoid too much syntactic embedding and structural ambiguity (resulting from the repetitive use of the same syntactic structure for different arguments, cf. example (76) which is disallowed).

ugi-ng agiita-lix

husband-1SG.POS/SG.POSM be.together.with-CONJ

'together with my husband,'

\begin{tabular}{|c|c|c|c|}
\hline Paavila- $\hat{x}$ & $\operatorname{amay}(u x)$ & ilaanu-ngin & guusti-ku-qing \\
\hline Paul-ABS & and & family-3(PL)POS/(PL)POSM & visit-IND-1SG \\
\hline
\end{tabular}

${ }^{18}$ One can also view phrases with interrogative particles followed by amayux as a construction type. 
*ugi-ng agiita-lix

husband-1SG.POS/SG.POSM be.together.with-CONJ

*'together with my husband,'

Paavila- $\hat{X}$ ilaanu-ngin ggiita-lix guusti-ku-qing

Paul-ABS family-3(PL)POS/(PL)POSM be.together.with-CONJ visit-IND-1SG

'I am visiting Paul together with his family'

In example (77), a simple coordinated structure would be ...ayagaan amaya asxinuun agiitalix... 'together with his wife and his daughter', which is not impossible; however, stylistically, the speaker prefers to coordinate the higher-level subordinate clauses ...ayagaan agiitalix amaya asxinuर̂x (agiitalix) kayux... 'together with his wife and (together with) (his) daughter as well,' effectively limiting the amount of information in a single clause, and the second verb is ellided:

Paavilâx ayaga-an agiita-lix

Paul-ABS wife-2SG.POS/SG.POSM.ABS be.together.with-CONJ

'Paul, together with his wife'

amaya asxinu- $\hat{X} \quad$ kayux amaligan $a-k u-\hat{x}$.

and daughter-ABS also there be-IND-3SG

'and his daughter also, will be there' (='Paul and his wife and daughter too will be there.') (F)

\section{Conclusions}

In most respects, coordination in Unangam Tunuu is not typologically unusual. Even the seemingly copious numbers of coordinators for the three basic coordinative types are explainable: few speakers actually make use of all of them, and a number of them are in fact morphosyntactic variations arising from the polysynthetic nature of the language (e.g. aguunulux/aguumulux). However, a variety of factors affect the use of coordinators in Unangam Tunuu, including the range of syntactic choices for expressing concepts, individual speaker preferences, social and pragmatic nuances in different expressions, and so forth. It would therefore be difficult to claim to know how coordination works by focusing on one illustrative coordinator of each type of coordination, or indeed by focusing on one type of coordination. For example, disjunction may not differ from conjunction in how it is constructed or in the effects it can have on the syntax; however, it has unique semantic requirements which affect the choice of coordinator and the range of contexts in which can be used.

Some of the restrictions on coordinate structure suggest that refinements in our understanding of other aspects of Unanga $\hat{x}$ grammar are necessary. For example, the requirement that sequential combinations be chained, rather than coordinated, suggests that sequential and simultaneous events should not be treated identically, despite the use of conjunctive mood in both cases and a long tradition which relates simultaneous or sequential action with the conjunctive mood in descriptions of Eskimo-Aleut languages. It is understandable that 
simultaneous and atemporal events should be viewed similarly while sequential events are treated differently, however subtle that difference may be.

On the other hand, some of the findings should be viewed somewhat critically. For example, while it is plausible that sequential events should be chained, as opposed to simultaneous or atemporal events, there is no obvious reason for oppositive or corrective adversative coordinate structures to be syntactically parallel while counterexpectative structures need not be, nor is there a reason for oppositive structures to allow the use of amayux while the others require $\operatorname{taga}(\hat{x})$. These apparent restrictions do not capture the semantic differences of the different types of adversative, and are therefore probably a result of insufficient data.

Finally, the description of coordination in Pribilof Islands Unangam Tunuu presented here is still incomplete. To truly understand the nature and importance of coordination in Unangam Tunuu, other possibly coordinating particles and their relation with subordinating forms need investigation. From what I have seen, it is unlikely that there are significant differences in the uses of coordination in the different dialects, but there are differences in other grammatical constructions, which may bring something to bear on coordinate constructions. For example, Eastern and Pribilovian speakers use the negative enclitic -ulux far more broadly and frequently than Atkan speakers do, and this is reflected in the disjunctive coordinators of the respective dialects (e.g. Eastern and Pribilovian aguunulux, Atkan aguun), and may be reflected in the subordinate constructions which express disjunction.

\section{Acknowledgments}

This material is based upon work supported by the National Science Foundation under Grant No. 0343968. Many thanks to the Unangax communities of Anchorage, St. Paul, and St. George for their generous participation and support.

\section{Abbreviations}

$\mathrm{ABS}=$ absolutive, $\mathrm{AN}=$ anaphoric, $\mathrm{AUG}=$ augmentative, $\mathrm{AUX}=$ auxiliary, $\mathrm{CAUS}=$ causative, $\mathrm{CESS}=$ cessative, $\mathrm{COND}=$ conditional, $\mathrm{CONJ}=$ conjunctive, $\mathrm{DAT}=$ dative, DEM.DIST $=$ demonstrative distal, DEM.PROX $=$ demonstrative proximal, $\mathrm{DIM}=$ diminuative, $\mathrm{DU}=$ dual, $\mathrm{DUB}=$ dubitative, $\mathrm{ENCL}=$ enclitic, $\mathrm{FUT}=$ future, $\mathrm{HAB}=$ habitual, $\mathrm{IND}=$ indicative, $\mathrm{IMP}=$ imperative, $\mathrm{INTEN}=$ intentional, $\mathrm{INTER}=$ interrogative $($ particle $), \mathrm{NEG}=$ negative, PART $=$ participial, PASS $=$ passive, $\mathrm{POS}=$ possessor, $\mathrm{POSM}=$ possessum, $\mathrm{PL}=$ plural, $\mathrm{REL}=$ relative, $\mathrm{SG}=$ singular, $\mathrm{SUP}=$ superlative, $\mathrm{TRANS}=$ transitive, $\mathrm{ZERO}=$ participial with zero morphology

\section{References}

Berge, Anna, and Dirks, Moses. 2009. Niiĝguis Matal Tunux̂tazangis / How the Atkans Talk: A Conversational Grammar, with 7 accompanying CD's; co-authored with Moses Dirks. Fairbanks: ANLC.

Bergsland, Knut, comp. 1994. Aleut Dictionary : Unangam tunudgusii. Fairbanks: ANLC. Bergsland, Knut. 1997. Aleut Grammar. Fairbanks: ANLC. 
Bergsland, Knut, and Dirks, Moses L., eds. 1990. Unangam Ungiikangin kayux Tunusangin / Unangam Uniikangis ama Tunuzangis / Aleut Tales and Narratives, collected 1909-1910 by Waldemar Jochelson. Fairbanks: ANLC.

Blühdorn, Hardarik. 2008. 'Subordination' versus 'Coordination'in Sentence and Text. ed. by Chathrine Fabricius-Hansen and Wiebke Ramm, 59-85. Amsterdam: John Benjamins.

Fabricius-Hansen, Cathrine; Wiebke Ramm; Kåre Solfjeld; Bergljot Behrens. 2005. Coordination, discourse relations, and information packaging - cross-linguistic differences. SPRIKreports, Reports of the project Languages in Contrast (Språk i kontrast). http://www.hf.uio.no/forskningsprosjekter/sprik. No. 31, September 2005.

Fortescue, Michael; Steven Jacobson; Lawrence Kaplan. 1994. Comparative Eskimo Dictionary with Aleut Cognates. Fairbanks: ANLC.

Haspelmath, Martin. 2004. Coordinating constructions: an overview. Coordinating Constructions, ed. by Martin Haspelmath, 3-39. Typological Studies in Language 58. Amsterdam: John Benjamins.

-----. 2007. Coordination. Language Typology and Syntactic Description II: Complex Constructions, ed. by Timothy Shopen, 1-51. $2^{\text {nd }}$ ed. Cambridge: Cambridge University Press.

Mauri, Caterina. 2008. Coordination Relations in the Languages of Europe and Beyond. Berlin: Mouton de Gruyter.

Mithun, Marianne. 1988. The grammaticization of coordination. Clause Combining in Grammar and Discourse. ed. by John Haiman and Sandra A. Thompson, 331-360. Amsterdam: John Benjamins.

Ohori, Toshio. 2004. Coordination in Mentalese. Coordinating constructions, ed. by Martin Haspelmath, 41-66. Typological Studies in Language 58. Amsterdam: John Benjamins.

Payne, John R. 1985. Complex phrases and complex sentences. Language Typology and Syntactic Description II: Complex Constructions, ed. by Timothy Shopen, 3-41. Cambridge: Cambridge University Press.

Rousseau, André. 2007. La coordination: approche méthodologique, critique et raisonnée des questions essentielles. La Coordination, ed. by André Rousseau, Louis Begioni, Nigel Quayle, and Daniel Roulland, 17-57. Rennes: Presses Universitaires.

Author's contact information:

Anna Berge

Alaska Native Language Center (ANLC)

P.O. Box 757680

University of Alaska Fairbanks

Fairbanks, AK 99775

amberge@alaska.edu 